\title{
Roles of thioredoxin and thioredoxin reductase in the resistance to oxidative stress in Lactobacillus casei
}

\author{
Masaki Serata, Tohru lino, Emi Yasuda and Tomoyuki Sako† \\ Yakult Central Institute for Microbiological Research, 1796 Yaho, Kunitachi, Tokyo 186-8650, \\ Japan
}

Correspondence

Masaki Serata

masaki-serata@yakult.co.jp

Received 16 August 2011

Revised 30 January 2012

Accepted 31 January 2012

\begin{abstract}
The Lactobacillus casei strain Shirota used in this study has in the genome four putative thioredoxin genes designated $\operatorname{trx} A 1, \operatorname{tr} x A 2, \operatorname{tr} x A 3$ and $\operatorname{tr} x A 4$, and one putative thioredoxin reductase gene designated $\operatorname{tr} x B$. To elucidate the roles of the thioredoxins and the thioredoxin reductase against oxidative stress in $L$. casei, we constructed gene disruption mutants, in which each of the genes $\operatorname{tr} x A 1, \operatorname{tr} x A 2$ and $\operatorname{tr} x B$, or both $\operatorname{trx} A 1$ and $\operatorname{tr} x A 2$ were disrupted, and we characterized their growth and response to oxidative stresses. In aerobic conditions, the $\operatorname{tr} x A 1$ (MS108) and the $\operatorname{trxA2}$ (MS109) mutants had moderate growth defects, and the $\operatorname{tr} x A 1 \operatorname{tr} x A 2$ double mutant (MS110) had a severe growth defect, which was characterized by elongation of doubling time and a lower final turbidity level. Furthermore, the $\operatorname{trx} B$ mutant (MS111), which is defective in thioredoxin reductase, lost the ability to grow under aerobic conditions, although it grew partially under anaerobic conditions. The growth of these mutants, however, could be substantially restored by the addition of dithiothreitol or reduced glutathione. In addition, MS110 and MS111 were more sensitive to hydrogen peroxide and disulfide stress than the wild-type. In particular, the stress sensitivity of MS111 was significantly increased. On the other hand, transcription of all these genes was only weakly affected by these oxidative stresses. Taken together, these results suggest that the thioredoxin-thioredoxin reductase system is the major thiol/disulfide redox system and is essential to allow the facultative anaerobe $L$. casei to grow under aerobic conditions.
\end{abstract}

\section{INTRODUCTION}

Facultative anaerobic lactic acid bacteria can grow well under aerobic conditions and are considered to have a system to eliminate or escape from the toxicity of oxygen and reactive oxygen species such as superoxide anions, hydrogen peroxide and hydroxyl radicals. Some lactic acid bacteria have oxygen-eliminating enzymes such as NADH oxidase, pyruvate oxidase and lactate oxidase (Goffin et al., 2004; Higuchi et al., 1993, 1999; Miyoshi et al., 2003; Sedewitz et al., 1984; Seki et al., 2004). Several antioxidant enzymes, including manganese superoxide dismutase (SOD) (Chang \& Hassan, 1997; Sanders et al., 1995), manganese catalase (Kono \& Fridovich, 1983) and NADH peroxidase (Miyoshi et al., 2003) have been identified in some lactic acid bacteria. In addition, several reports of genome sequences of lactic acid bacteria indicate the existence of

tPresent address: Yakult Europe BV, Schutsluisweg 1, 1332 EN Almere, The Netherlands.

Abbreviations: DTT, dithiothreitol; GSH, glutathione.

The GenBank/EMBL/DDBJ accession numbers for the nucleotide sequences of $\operatorname{tr} x A 1, \operatorname{tr} x A 2, \operatorname{tr} x A 3, \operatorname{tr} x A 4$ and $\operatorname{tr} x B$ are $A B 617512-$ AB617516. these stress resistance genes (Altermann et al., 2005; Chaillou et al., 2005; Kleerebezem et al., 2003; van de Guchte et al., 2006). However, the variety and number of stress resistance genes are different in each species. In Lactobacillus casei, five genome sequences have been reported (Ai et al., 2011; Chen et al., 2011; Makarova et al., 2006; Mazé et al., 2010; Zhang et al., 2010) and comparative genome analysis has been performed (Cai et al., 2009). This reveals that L. casei strains have genes coding for enzymes involved in oxidative stress resistance such as $\mathrm{NADH}$ oxidase, $\mathrm{NADH}$ peroxidase, lactate oxidase and SOD in common.

The inside of a living cell is generally kept in a reduced state. One of the sensitivities to oxidative stress is due to thiol oxidation and/or the inability to reduce thiol groups in enzymes. Thioredoxin is a small protein that is involved in maintaining the thiol/disulfide balance in both prokaryotic and eukaryotic cells (Holmgren, 1985), and was originally identified as the electron donor for ribonucleotide reductase in Escherichia coli (Laurent et al., 1964). All thioredoxins identified so far possess a conserved CXXC motif at their active site. Thioredoxin plays a significant role in cellular redox processes, including protein repair and defence against oxidative stress (Arnér \& Holmgren, 
2000). This motif is interchangable between the oxidized disulfide and the reduced dithiol forms. Oxidized thioredoxin is reduced by a flavoenzyme, thioredoxin reductase at the expense of NADPH (Carmel-Harel \& Storz, 2000; Holmgren, 1985). E. coli has a glutathione-glutaredoxindependent reduction system as well as a thioredoxindependent reduction system. However, glutathione is absent in extracts of many Gram-positive bacteria including L. casei (Fahey et al., 1978), indicating that those organisms do not produce and utilize glutathione in the reduction system. Therefore, the thioredoxin-thioredoxin reductase system is considered to be the only reduction system in $L$. casei.

L. casei strain Shirota is one of the most intensively studied probiotics (Asahara et al., 2001; Matsumoto et al., 2005; Matsuzaki et al., 2004; Shida et al., 2006) and its complete genome has been sequenced (unpublished data). This strain is used in fermented milk products and has high growth and good viability under aerobic conditions, which implies that the intracellular thiol/disulfide balance and redox system is fully active in this strain. However, the mechanisms for maintenance of the thiol/disulfide balance and oxidative stress resistance in $L$. casei are largely unknown and need to be clarified. While the contribution of antioxidant enzymes to the resistance to oxygen and reactive oxygen species in lactic acid bacteria has been extensively studied (Chang \& Hassan, 1997; Kono \& Fridovich, 1983; Miyoshi et al., 2003), few studies have examined the role of the thioredoxinthioredoxin reductase system. In this study, we focused on the role of the thioredoxin-thioredoxin reductase system in growth and survival under aerobic conditions in L. casei by using gene disruption mutants of L. casei strain Shirota. Our findings show that the thioredoxin-thioredoxin reductase system, which controls the intracellular thiol/disulfide balance, also plays a pivotal role in aerobic growth in L. casei.

\section{METHODS}

Strains, plasmids, media and growth conditions. The strains and plasmids used in this study are listed in Table 1. L. casei strain Shirota (YIT 9029) was used as the wild-type. E. coli JM109 (Toyobo) was used as the competent cells for DNA transformation. Plasmid pYSSE3 (Yasuda et al., 2008) was used as a cloning vector for insertion and deletion mutagenesis. Lactic acid bacteria were grown at $37{ }^{\circ} \mathrm{C}$ in MRS medium (Becton Dickinson). E. coli was grown at $37{ }^{\circ} \mathrm{C}$ in $\mathrm{LB}$ medium (Sambrook \& Russel, 2001). Erythromycin (Abbott) was added to a final concentration of $20 \mu \mathrm{g} \mathrm{ml}^{-1}$ for lactic acid bacteria and $500 \mu \mathrm{g} \mathrm{ml}^{-1}$ for E. coli. The optical density of the cultures was measured at $590-660 \mathrm{~nm}$ by using a Klett-Summerson photoelectric colorimeter (Klett MFG). To generate aerobic conditions, the medium was dispensed into test tubes with silicon caps which allowed free air exchange (for aerobic conditions) or loose aluminium caps (for static aerobic conditions). To generate anaerobic conditions, the medium was prepared by boiling for $20 \mathrm{~min}$ followed by replacing the oxygen in the medium with nitrogen by bubbling it into the medium for $30 \mathrm{~min}$. The medium was dispensed into test tubes, and the head space was filled with nitrogen gas. Test tubes were sealed with a butyl rubber plug to avoid oxygen contamination during the course of their anaerobic incubations. The cells were cultured with shaking at 160 r.p.m. under aerobic conditions or without shaking under anaerobic and static aerobic conditions. The $\operatorname{tr} x B$ mutant was precultivated under anaerobic conditions; wild-type and other mutants were grown under static aerobic conditions. Growth analysis of wild-type and mutants under aerobic or anaerobic conditions was performed in three independent experiments. The data are shown as the mean \pm SD of three independent experiments. The growth data of the wild-type and mutants were analysed by using a two-tailed Student's $t$-test. $P<0.05$ was considered as significant.

Construction of insertion and deletion mutants. Plasmid pYSSE3 is a derivative of a shuttle plasmid vector pBE31 (Kiwaki \& ShimizuKadota, 2002), which is devoid of the origin of replication (ori) of $\operatorname{pAM} \beta 1$. Recombinant plasmids for insertional mutagenesis were constructed as follows. The truncated fragment of the target gene was amplified by PCR using L. casei strain Shirota genomic DNA as a template, the primer pairs listed in Table 2 and KOD Plus DNA

Table 1. Bacterial strains and plasmids used in this study

\begin{tabular}{|c|c|c|}
\hline Strain or plasmid & Genotype or phenotype & Source or reference \\
\hline \multicolumn{3}{|l|}{ Strains } \\
\hline \multicolumn{3}{|l|}{ L. casei } \\
\hline Shirota (YIT 9029) & Wild-type & Our collection \\
\hline MS108 & $\operatorname{tr} x A 1::$ pYSSE3- $\Delta \operatorname{tr} x A 1, \mathrm{Em}^{\mathrm{r}}$ & This study \\
\hline MS109 & $\operatorname{tr} x A 2:: \mathrm{pYSSE} 3-\Delta \operatorname{tr} x A 2, \mathrm{Em}^{\mathrm{r}}$ & This study \\
\hline MS110 & Deletion in $\operatorname{tr} x A 1$ gene, $\operatorname{tr} x A 2::$ pYSSE3- $\triangle \operatorname{tr} x A 2, \mathrm{Em}^{\mathrm{r}}$ & This study \\
\hline MS111 & $\operatorname{tr} x B::$ pYSSE3- $\Delta \operatorname{tr} x B, \mathrm{Em}^{\mathrm{r}}$ & This study \\
\hline \multicolumn{3}{|l|}{ E. coli } \\
\hline JM109 & Commercial strain purchased from Toyobo & \\
\hline \multicolumn{3}{|l|}{ Plasmids } \\
\hline pYSSE3 & $\begin{array}{l}\text { E. coli cloning vector carrying pUC19 ori region, pAM } \beta 1 \text { erythromycin } \\
\text { resistance gene and multicloning sites }\end{array}$ & Yasuda et al. (2008) \\
\hline pYSSE3- $\Delta \operatorname{trx} A 1$ & pYSSE3 carrying truncated fragment of $\operatorname{tr} x A 1$ & This study \\
\hline pYSSE3- $\Delta \operatorname{tr} x A 2$ & pYSSE3 carrying truncated fragment of $\operatorname{tr} x A 2$ & This study \\
\hline pYSSE3- $\Delta \operatorname{tr} x B$ & pYSSE3 carrying truncated fragment of $\operatorname{tr} x B$ & This study \\
\hline pYSSE3- $\Delta$ trxA1-del & $\begin{array}{l}\text { pYSSE3 carrying upstream region with } \mathrm{N} \text { terminus of } \operatorname{tr} x A 1 \text { and } \\
\text { downstream region with } \mathrm{C} \text { terminus of } \operatorname{tr} x A 1\end{array}$ & This study \\
\hline
\end{tabular}


Table 2. Primers used in this study

The restriction enzyme sites are indicated (underlined).

\begin{tabular}{|c|c|c|c|c|}
\hline \multirow[t]{2}{*}{ Target gene } & \multicolumn{2}{|c|}{ Primer sequence $\left(5^{\prime}-3^{\prime}\right)$} & \multicolumn{2}{|c|}{$\begin{array}{l}\text { Restriction } \\
\text { enzyme site }\end{array}$} \\
\hline & Forward & Reverse & Forward & Reverse \\
\hline \multicolumn{5}{|c|}{ Construction of insertion mutants } \\
\hline $\operatorname{trxA1}$ & CCGGAATTCTGGCGTCACCCTAACAGAT & TAGTCTAGATGATAGCCAACAAGCTTCTC & EcoRI & $X b a \mathrm{I}$ \\
\hline $\operatorname{tr} x A 2$ & CGGGATCCGCAGATTGGTGCTCGGATTG & AAACTGCAGCGTTAAAGGCAATAAAGCTC & BamHI & Pst I \\
\hline \multicolumn{5}{|c|}{ Confirmation of insertion mutants } \\
\hline $\operatorname{trxA1}$ & TTAAGTTGGGTAACGCCAGG & ACTGTGTGCCTTCATAATCG & & \\
\hline $\operatorname{trx} A 2$ & TTAAGTTGGGTAACGCCAGG & ACGCTGGTTGATTATAACTG & & \\
\hline $\operatorname{trx} B$ & TTAAGTTGGGTAACGCCAGG & AATCAAGCTTTAATCTCAATA & & \\
\hline \multicolumn{5}{|c|}{ Construction of deletion mutants } \\
\hline $\operatorname{tr} x A 1-5^{\prime}$ & CCGGAATTCCGATAAAATCATCAAGCAAC & CCCAAGCTTGGTTTCCGTCTTGTAGTTTG & EcoRI & HindIII \\
\hline $\operatorname{trx} A 1$ & CGGCCCTTGCCGGATGCA & TTTCTGCCAATTTGTCGATGAC & & \\
\hline $\operatorname{tr} x A 2$ & AACCAGCTATGCCTGAAATTGAG & GCGATCAACCGCGATGA & & \\
\hline $\operatorname{trx} A 3$ & GGGCATTATGTCAGTACCCACCT & GGTAAACACCTGTCACTTTTTCGC & & \\
\hline $\operatorname{tr} x A 4$ & GGCAAAGTGGTGACGCAGTA & CCAGCCAGCACTTTGTCGAT & & \\
\hline $\operatorname{trx} B$ & CCGGCCCAGGTGGTATG & CAGCATCAGCACAGATAAATTGG & & \\
\hline $\mathrm{NADH}$ oxidase & CGACCCATGCCGGTACA & CGTACACGGTGACGTCATAATCA & & \\
\hline NADH peroxidase & CGGCAATCAATGCTGATGTG & CTGCGTCGTGCCGTTCT & & \\
\hline 16SrRNA & TGGTTGTCGTCAGCTCGTG & TCTTACTAGAGTGCCCAACT & & \\
\hline
\end{tabular}

polymerase (Toyobo). The fragment was digested with relevant restriction enzymes at both ends (Table 2). The fragment was cloned into pYSSE3, which had previously been digested with the same restriction enzymes, followed by treatment with calf intestinal alkaline phosphatase (Takara). Each recombinant plasmid was purified by using the Wizard Plus SV Minipreps DNA purification system (Promega) and transferred into L. casei strain Shirota by electroporation (Yasuda et al., 2008). Briefly, cells were grown in $20 \mathrm{ml}$ MRS broth to early exponential phase and harvested by centrifugation. Cells were washed once with an equal volume of $1 \mathrm{mM}$ HEPES ( $\mathrm{pH} 7.0)$, followed by washing with a $0.5 \mathrm{vol} .10 \%(\mathrm{w} / \mathrm{v})$ glycerol and then $1 \mathrm{ml} 10 \%(\mathrm{w} / \mathrm{v})$ glycerol. Cells were suspended in $1 / 200$ of the original culture volume in $10 \%(\mathrm{w} / \mathrm{v})$ glycerol. Electroporation was done with $40 \mu \mathrm{l}$ competent cells and 1-2 $\mu$ l plasmid DNA solutions in a $2 \mathrm{~mm}$ path cuvette at a $25 \mu \mathrm{F}$ capacitance, $200 \Omega$ resistance and $1.5 \mathrm{kV}$ voltage with a Gene Pulser II Electroporation System (BioRad). Cells were transferred to $1 \mathrm{ml}$ MRS broth and then incubated at $37{ }^{\circ} \mathrm{C}$ for $60 \mathrm{~min}$ and plated onto MRS agar plates containing $20 \mu \mathrm{g}$ erythromycin $\mathrm{ml}^{-1}$ and incubated at $37{ }^{\circ} \mathrm{C}$ for 2 or 3 days. When colonies did not appear under these conditions, cells were plated onto MRS plates containing $20 \mu \mathrm{g}$ erythromycin $\mathrm{ml}^{-1}$ and $5 \mathrm{mM}$ dithiothreitol (DTT), and incubated under anaerobic conditions. Erythromycin-resistant clones were selected and plasmid integration was confirmed by PCR with appropriate primers (Table 2). One primer was designed upstream of the multicloning site of pYSSE3 and the other was downstream of the target gene in the chromosome.

In order to develop the $\operatorname{tr} x A 1 \operatorname{tr} x A 2$ double mutant, the $\operatorname{tr} x A 1$ deletion mutant, which is sensitive to erythromycin, was constructed. A recombinant plasmid for deletion mutagenesis was constructed as follows: two fragments containing the $5^{\prime}$ - and $3^{\prime}$-terminal ends of the target gene were amplified with the primer sets listed in Table 2. These fragments were cloned into pYSSE3 in the same order as on the chromosome to obtain in-frame deletions within the genes. L. casei strain Shirota was transformed with the plasmid, and an erythromycin-resistant clone was selected first. This clone was confirmed as including the recombinant plasmid integrated into either the $5^{\prime}$ - or $3^{\prime}$-terminal side of the respective gene regions by homologous recombination. After several cycles of subculturing $[0.1 \%(\mathrm{v} / \mathrm{v})$ inoculation into fresh medium followed by full growth], erythromycin-sensitive clones were screened and checked for the reversion or deletion by PCR with appropriate primers (Table 2) that were able to amplify the target gene. To obtain the $\operatorname{tr} x A 1 \operatorname{trxA} 2$ double mutant, we transferred a recombinant plasmid containing a truncated fragment of $\operatorname{tr} x A 2$ gene as described above.

Inhibition of growth by hydrogen peroxide. Overnight cultures were inoculated at $1 \%(\mathrm{v} / \mathrm{v})$ into $4 \mathrm{ml}$ MRS medium. Strains were grown at $37{ }^{\circ} \mathrm{C}$ under static aerobic conditions (WT, MS108, MS109 and MS110) or anaerobic conditions (MS111). Hydrogen peroxide at $0.5,1$ or $2 \mathrm{mM}$ was added to cultures after $7 \mathrm{~h}$ incubation. The turbidity of the culture was measured by using a Klett-Summerson photoelectric colorimeter. Experiments were performed three times independently. The data shown are mean \pm SD of three independent experiments.

Treatments with reducing agents and diamide. Overnight cultures were inoculated at $1 \%(\mathrm{v} / \mathrm{v})$ into $4 \mathrm{ml}$ MRS medium with reducing agents or diamide. Strains were grown at $37{ }^{\circ} \mathrm{C}$ under static aerobic conditions or anaerobic conditions (only for diamide treatment). Reducing agents and diamide added to cultures were used at the following concentrations: DTT, $1 \mathrm{mM}$; glutathione (GSH), $1 \mathrm{mM}$; cysteine (Cys), $1 \mathrm{mM}$; diamide, 1 or $5 \mathrm{mM}$. Klett units were measured after $24 \mathrm{~h}$ incubation. Experiments were performed at least 
three times independently. The data shown are mean \pm SD of three independent experiments.

RNA isolation. An oxidative stress response was induced by cell exposure to $\mathrm{O}_{2}$ or $\mathrm{H}_{2} \mathrm{O}_{2}$. The exposure to $\mathrm{O}_{2}$ was performed as follows. A single $100 \mathrm{ml}$ culture of $L$. casei strain Shirota, which was inoculated at $1 \%(\mathrm{v} / \mathrm{v})$ with an overnight culture, was grown in MRS broth for $7 \mathrm{~h}$ under anaerobic conditions and divided into two $50 \mathrm{ml}$ aliquots. One aliquot was grown for $30 \mathrm{~min}$ under anaerobic conditions as a control and the other was grown for $30 \mathrm{~min}$ under aerobic conditions by shaking at 160 r.p.m. in a water bath shaker. The exposure to $\mathrm{H}_{2} \mathrm{O}_{2}$ was performed as follows. A single $100 \mathrm{ml}$ culture of $L$. casei strain Shirota, which was inoculated at $1 \%(\mathrm{v} / \mathrm{v})$ with an overnight culture, was grown in MRS for $7 \mathrm{~h}$ under static aerobic conditions and divided into two aliquots. One aliquot was grown for $30 \mathrm{~min}$ under static aerobic conditions as a control and $0.5 \mathrm{mM} \mathrm{H}_{2} \mathrm{O}_{2}$ was added to the other; this culture was also grown for $30 \mathrm{~min}$ under static aerobic conditions. Two mililitres of each culture was added to $4 \mathrm{ml}$ RNAprotect Bacteria Reagent (Qiagen). The mixture was incubated at room temperature for $5 \mathrm{~min}$. The cells were harvested by centrifugation for $10 \mathrm{~min}$ at $5000 \mathrm{~g}$. The cells were suspended in $200 \mu \mathrm{l} \mathrm{TE}$ buffer $(10 \mathrm{mM}$ Tris/HCl, $1 \mathrm{mM}$ EDTA, $\mathrm{pH}$ 8.0) containing $15 \mathrm{mg}$ lysozyme $\mathrm{ml}^{-1}$ (Sigma-Aldrich) and $0.05 \mathrm{mg}$ $\mathrm{N}$-acetylmuramidase $\mathrm{SG} \mathrm{\textrm {ml } ^ { - 1 }}$ (Seikagaku) and incubated at room temperature for $10 \mathrm{~min}$ with occasional vortexing. Total RNA was purified by using the RNeasy Mini kit (Qiagen) according to the protocol provided by the supplier. Contaminating DNA was digested by using the RNase-Free DNase set kit (Qiagen) in the purification step. RNA integrity for all samples was confirmed with an Agilent 2100 Bioanalyser (Agilent Technologies). RNA was isolated from three independent cultures.

Quantitative real-time PCR assays. cDNA was synthesized by using a PrimeScript 1st strand cDNA Synthesis kit (Takara) according to the protocol provided by the supplier. Total RNA $(1 \mu \mathrm{g})$ was used as a template. Quantitative real-time PCR was performed using the ABI 7500 Real-time PCR System (Applied Biosystems) with SYBR Premix ExTaq (Takara). The primers were designed to amplify products of 47 $82 \mathrm{bp}$ (Table 2). The reaction mixture contained $12.5 \mu \mathrm{l} 2 \times$ SYBR Premix ExTaq, $0.5 \mu \mathrm{l} 10 \mu \mathrm{M}$ forward primer, $0.5 \mu \mathrm{l} 10 \mu \mathrm{M}$ reverse

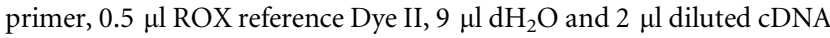

template. All reactions were run in duplicate for each of three independent RNA samples. The gene expression values were normalized using 16S rRNA as internal standard. A melting curve analysis was performed after each run to confirm the amplification specificity. Data were analysed using the Sequence Detection Software (Applied Biosystems) by applying the standard-curve quantification method. Standard curves for both internal standard and target genes were generated by amplifying tenfold serial dilutions of cDNA. The gene expression data from quantitative real-time PCR were analysed by twotailed Student's $t$-test. $P<0.05$ was considered as significant.

Database search, homology search and multiple alignment. Primary sequences of $L$. casei strain Shirota $\operatorname{tr} x A$ and $\operatorname{tr} x B$ were identified with BLASTN and BLASTP algorithms provided from the NCBI database (http://blast.ncbi.nlm.nih.gov/Blast.cgi). Homology searches were performed by using GENETYX software. Multiple alignment was performed by using the CLUSTALW2 programme (http://www.ebi.ac.uk/ Tools/msa/clustalw2/).

\section{RESULTS}

\section{Thioredoxin-thioredoxin reductase system in L. casei}

Bioinformatic analysis found four thioredoxin genes and two thioredoxin reductase-like genes in the L. casei strain Shirota genome sequence. Four thioredoxins, which are designated $\operatorname{tr} x A 1, \operatorname{tr} x A 2, \operatorname{tr} x A 3$ and $\operatorname{tr} x A 4$, have a common CXXC motif, which is the active site of thioredoxin and thioredoxin reductase. However, the deduced amino acid sequences of these genes showed low homology to each other except for the locus of the active site (Fig. 1). The two thioredoxin reductase-like genes identified from sequence similarity to known sequences are $29 \%$ identical in amino acid sequence to each other, but one of them does not have a CXXC motif, suggesting that this protein does not catalyse

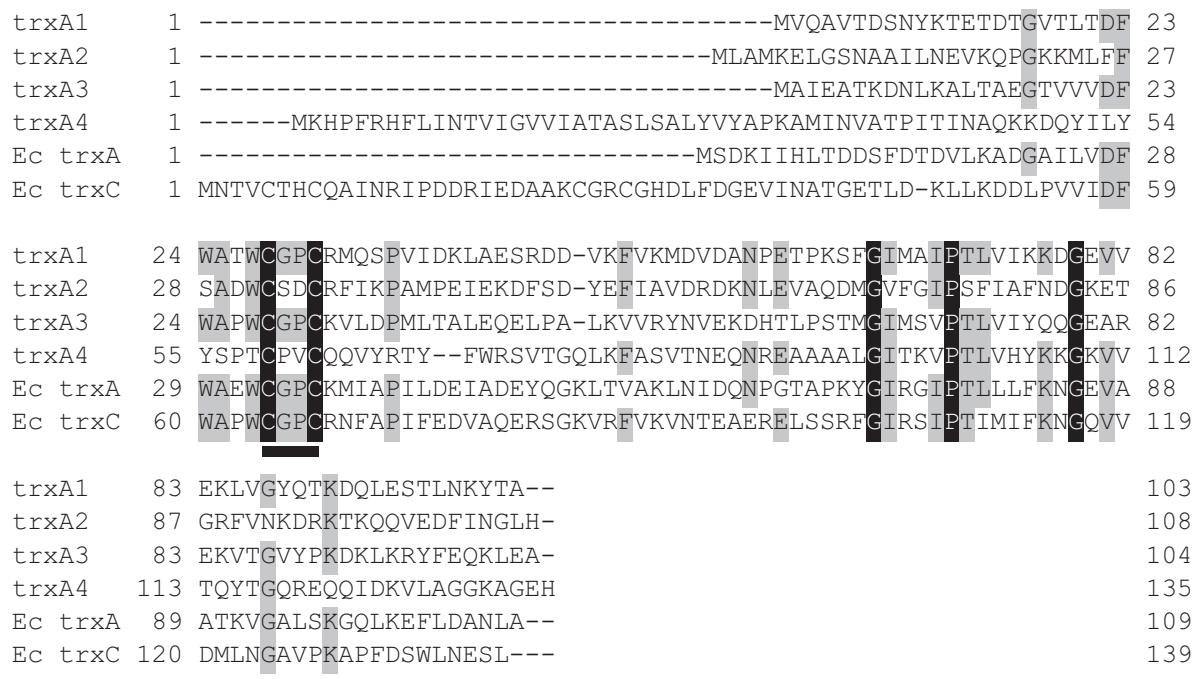

Fig. 1. Multiple alignment of the amino acid sequences of $L$. casei strain Shirota thioredoxin and $E$. coli thioredoxin. The residues with a black background represent residues conserved in all sequences; those with a grey background represent residues conserved in at least $50 \%$ of all sequences. The CXXC active site is indicated by thick line. 
reduction of oxidized thioredoxin and has some other functions. Similar sequences are found in some Grampositive bacteria such as lactobacilli, L. lactis and Bacillus subtilis. Among these, the $B$. subtilis yumC product is known to function as a ferredoxin $\mathrm{NADP}^{+}$reductase (Seo et al., 2004) and has high amino acid identity with the corresponding protein in L. casei strain Shirota, implying that it may have the same function. Therefore, we designated the gene that has a CXXC motif as $\operatorname{tr} x B$, and eliminated the yumC-like gene from subsequent analysis in this study.

All sequenced $L$. casei strains except $L$. casei Zhang also have four thioredoxin genes and a thioredoxin reductase gene. $L$. casei Zhang does not have a trxA4 gene. These amino acid sequences in $L$. casei strain Shirota are identical to those of BL23, BD-II and LC2W. Other strains also show high similarity with $L$. casei strain Shirota (ATCC 334: $100 \%$ TrxA1, A2, A3, $92 \%$ TrxA4, $99 \%$ TrxB; Zhang: $100 \%$ TrxA1, A2, A3, $99 \%$ TrxB).

\section{Construction and growth of gene disruption mutants}

To elucidate the roles of thioredoxins and thioredoxin reductase in the tolerance to oxidative stresses, we constructed gene disruption mutants. We focused on the $\operatorname{tr} x A 1, \operatorname{tr} x A 2$ and $\operatorname{tr} x B$ genes and disrupted these as described in Methods. The $\operatorname{tr} x A 1$ and $\operatorname{tr} x A 2$ genes were chosen from the four thioredoxin genes in this study because of the high expression rates of these genes in both oxidatively stressed and unstressed conditions (M. Serata, unpublished results). The trxA1, $\operatorname{trx} A 2$ and $\operatorname{trx} B$ mutants (MS108, MS109 and MS111, respectively) were constructed by insertional mutagenesis. The $\operatorname{tr} x A 1 \operatorname{tr} x A 2$ double mutant (MS110) was obtained in two steps: firstly $\operatorname{tr} x A 1$ was disrupted by deletion mutagenesis and secondly $\operatorname{trx} A 2$ was disrupted by insertional mutagenesis. Although we obtained the $\operatorname{tr} x A 1$ mutant and the $\operatorname{tr} x A 2$ mutant easily under aerobic conditions, efforts to isolate the $\operatorname{tr} x A 1 \operatorname{tr} x A 2$ double mutant and the $\operatorname{tr} x B$ mutant were unsuccessful until the selection medium was anaerobically incubated in the presence of $1 \mathrm{mM}$ DTT. The $\operatorname{tr} x B$ mutant formed very small colonies even under these conditions.

Under anaerobic conditions, MS108 and MS109 grew as well as the wild-type strain, but MS110 and MS111 showed significant growth defects. While MS110 showed a slight but significant delay in growth during exponential phase, MS111 showed significant growth delay during the exponential phase and the final level of turbidity was significantly lower (Fig. 2b). Under aerobic conditions, MS108 and MS109 had a moderate growth defect, although growth of MS109 was only significantly different at one time point. MS110 had a significant growth defect in both doubling time and final turbidity level (Fig. 2a). In contrast, MS111 did not grow under aerobic conditions (Fig. 2a). These results show that TrxB has an essential role in aerobic growth, while different TrxAs contribute to aerobic growth partially and in a complementary manner.

The sensitivity of these mutants to oxidative stress was further analysed. We investigated the effect of hydrogen peroxide on the growth of the mutants. Strains were grown in MRS broth under static aerobic conditions (wild-type, MS108, MS109 and MS110) or under anaerobic conditions (MS111). Hydrogen peroxide was added after $7 \mathrm{~h}$ incubation. The growth of the wild-type strain and mutants was inhibited in proportion to the hydrogen peroxide concentration. MS109 grew even in the presence of $1 \mathrm{mM}$ hydrogen peroxide, and the growth of MS108 was inhibited at $1 \mathrm{mM}$. The growth of MS110 was significantly delayed with $0.5 \mathrm{mM}$ $\mathrm{H}_{2} \mathrm{O}_{2}$. The growth of MS111 was severely affected in the presence of $0.5 \mathrm{mM}$ hydrogen peroxide even in the anaerobic conditions (Fig. 3). These results indicate that the active thioredoxin-thioredoxin reductase system is important for resisting the toxic effects of hydrogen peroxide as well.

\section{Effects of reducing agents on the growth of mutants}

In order to investigate whether the growth defects of the mutants were caused by thiol/disulfide imbalance, we
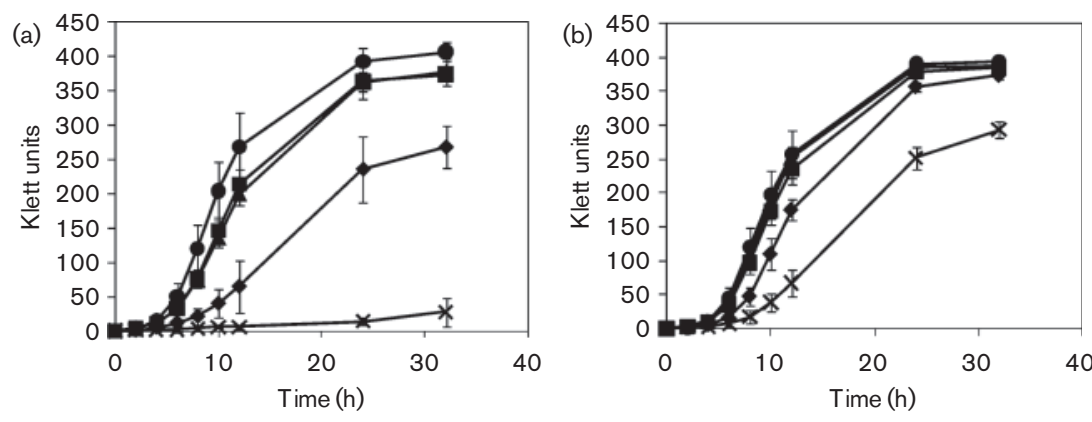

Fig. 2. Growth of $L$. casei strain Shirota and gene disruption mutants under aerobic (a) or anaerobic (b) conditions. Overnight MRS cultures were inoculated into fresh MRS cultures. $\quad$, wild-type strain; $\boldsymbol{\Delta}, \mathrm{MS} 108$ (trxA1 mutant); $\mathbf{\square}$, MS109 (trxA2 mutant); - MS110 (trxA1 trxA2 double mutant); $\times$, MS111 (trxB mutant). The data are means \pm SD of three independent experiments. Time points when the turbidity of mutants were significantly lower than that of the wild-type were as follows: MS109 $32 \mathrm{~h}$ (aerobic conditions), MS110 4-32 h (aerobic conditions) and 6$32 \mathrm{~h}$ (anaerobic conditions), MS111 4-32 h (aerobic conditions) and 6-32 h (anaerobic conditions) (Student's $t$-test $P<0.05$ ). 

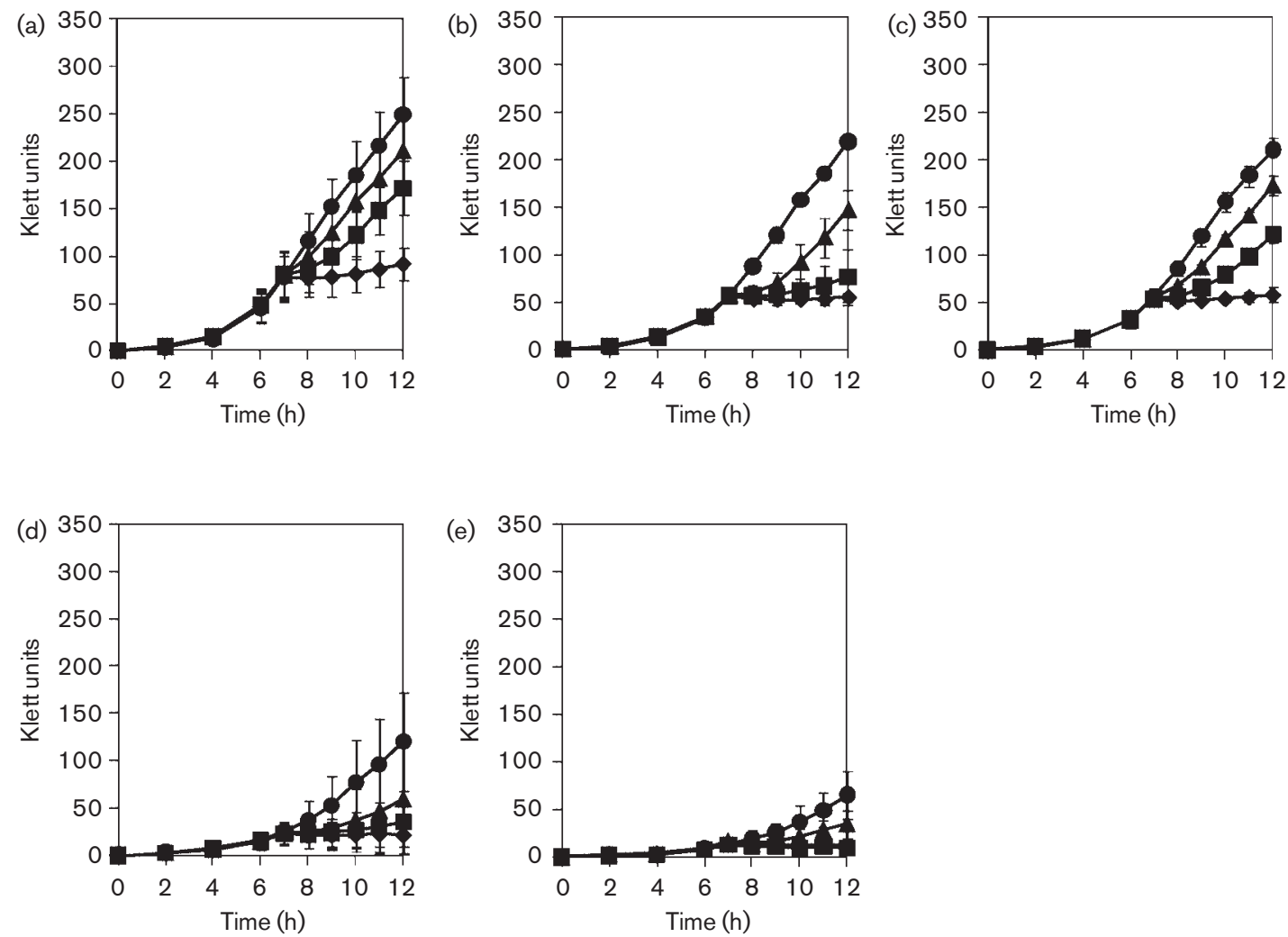

Fig. 3. Effect of adding hydrogen peroxide on the growth of $L$. casei strain Shirota and gene disruption mutants. (a) Wild-type, (b) MS108 (trxA1 mutant), (c) MS109 (trxA2 mutant), (d) MS110 (trxA1 trxA2 double mutant) and (e) MS111 (trxB mutant). Strains were grown in MRS broth under static aerobic (wild-type, MS108, MS109 and MS110) or anaerobic (MS111) conditions. Hydrogen peroxide was added after $7 \mathrm{~h}$ of incubation. $\bullet$, no hydrogen peroxide; $\boldsymbol{\Delta}, 0.5 \mathrm{mM} ; \mathbf{\square}, 1.0 \mathrm{mM} ; \boldsymbol{}$ $2.0 \mathrm{mM}$. The data are mean $\pm \mathrm{SD}$ of three independent experiments.

added thiol compounds to the medium. Fig. 4 shows the effects of DTT, GSH or Cys on the growth of the wild-type and mutants. Strains were grown in MRS broth under static aerobic conditions with $1 \mathrm{mM}$ thiol compounds. Klett units were measured after $24 \mathrm{~h}$ incubation. The growth of the wild-type was not affected by the addition of any of the compounds. The growth defects of MS110 and MS111 were eliminated by adding DTT or GSH under static aerobic conditions. In particular, the growth phenotype of MS111 was dramatically restored under static aerobic conditions by the addition of these agents. In contrast, the addition of cysteine to the medium resulted in inhibition of the growth of MS109, MS110 and MS111, while it did not affect the growth of wild-type and MS108 (Fig. 4). This implies that cysteine has toxic effects on the growth of mutants defective in the thioredoxin-thioredoxin reductase system.

\section{Sensitivity to diamide}

Diamide is a thiol-oxidizing agent (Kosower \& Kosower, 1995) that mimics damage due to oxygen exposure under anaerobic conditions. We analysed the influence of diamide on the growth and survival of these mutants under static aerobic conditions or anaerobic conditions. We found that the growth of the wild-type strain was slightly affected by the addition of 1 or $5 \mathrm{mM}$ diamide; however, MS110 and MS111 were sensitive to diamide even under anaerobic conditions (Fig. 5). MS108 and MS109 were partially affected by the addition of diamide. These results suggest that the thioredoxin-thioredoxin reductase system plays a role in maintaining the intracellular thiol/disulfide balance towards the reduced state in both static aerobic and anaerobic conditions.

\section{Transcription analysis of $t r x$ genes}

In order to investigate whether thioredoxin and thioredoxin reductase genes are induced by oxidative stresses, the expression of these genes after exposure to oxygen and hydrogen peroxide was examined by quantitative real-time PCR assays. In addition, in order to compare this to other antioxidant genes, the expression level of $\mathrm{NADH}$ oxidase $(n o x 2)$ and NADH peroxidase ( $n p x)$ genes, functioning as oxygen and hydrogen peroxide eliminators, respectively, were determined. These data are expressed as the mean fold 


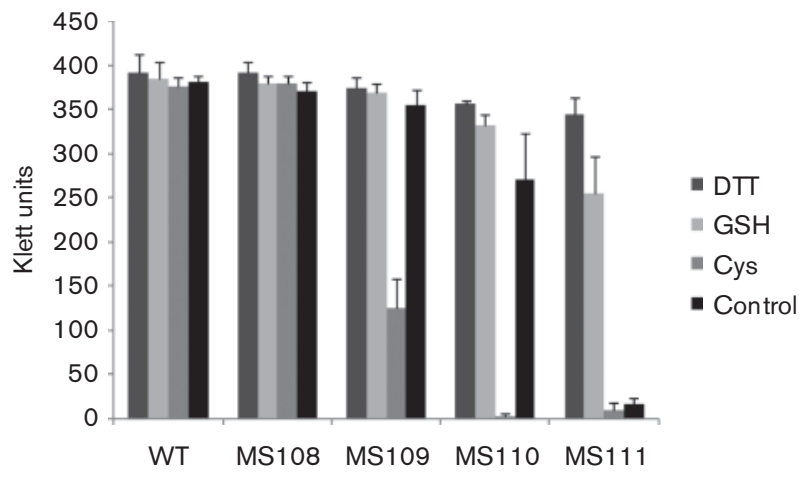

Fig. 4. Effect of adding reducing agents on the growth of $L$. casei strain Shirota and gene disruption mutants. Strains were grown in MRS cultures under static aerobic conditions with $1 \mathrm{mM}$ DTT, GSH or Cys. Klett units were measured after $24 \mathrm{~h}$ incubation. The control had no agent added. The data are means \pm SD of at least three independent experiments. Strains: WT (wild-type), MS108 (trxA1 mutant), MS109 (trxA2 mutant), MS110 (trxA1 trxA2 double mutant) and MS111 (trxB mutant).

change compared with each unstressed control (Fig. 6). The expression of $\operatorname{tr} x A 1, \operatorname{tr} x A 2$ and $\operatorname{tr} x B$ after adding hydrogen peroxide was slightly but significantly increased. Furthermore, the expression of other genes did not change significantly following these treatments. On the other hand, $\mathrm{NADH}$ oxidase was significantly induced by oxygen stress and NADH peroxidase was significantly induced by both oxygen stress and hydrogen peroxide stress.

\section{DISCUSSION}

The thioredoxin-thioredoxin reductase system and the glutathione-glutaredoxin system control the thiol/disulfide balance in many prokaryotic and eukaryotic cells and play an important role in sustaining life (Carmel-Harel \& Storz,
2000). In bacteria that do not synthesize glutathione, the thioredoxin-thioredoxin reductase system may be the only thiol/disulfide redox control system. Thioredoxin in $B$. subtilis and thioredoxin reductase in $S$. aureus were reported to be essential for their survival (Scharf et al., 1998; Uziel et al., 2004). Furthermore, a deletion mutant in the thioredoxin reductase gene in $B$. fragilis was unable to grow without a reductant (Rocha et al., 2007). In lactic acid bacteria, it has been reported that the overproduction of thioredoxin reductase in Lactobacillus plantarum WCFS1 improved tolerance towards oxidative stress (Serrano et al., 2007).

In this study, we showed that a thioredoxin reductasedeficient mutant of $L$. casei strain Shirota was not able to grow under aerobic conditions (Fig. 2), while the growth of $\operatorname{tr} x A 1, \operatorname{tr} x A 2$ or the $\operatorname{tr} x A 1 \operatorname{tr} x A 2$ double mutant was affected to some extent. The partial growth defect of $\operatorname{tr} x A 1, \operatorname{tr} x A 2$ and the $\operatorname{tr} x A 1 \operatorname{tr} x A 2$ double mutant indicates that $\operatorname{tr} x A 3$ and/or $\operatorname{tr} x A 4$ are also functioning.

In contrast with the inability to grow in aerobic conditions, MS111 can grow partially under anaerobic conditions. Rocha et al. (2007) reported that a deletion mutant in the thioredoxin reductase gene in $B$. fragilis was unable to grow in semi-defined medium but was able to grow in rich medium. This implies that the ability to grow under anaerobic conditions could be attributed to the presence of thiol compounds in the medium. Therefore, it is probable that the growth ability of MS111 of L. casei strain Shirota in anaerobic MRS broth can also be attributed to the presence of thiol compounds such as glutathione in the medium. Confirmation of this hypothesis, however, will require future studies in a chemically defined medium.

Both DTT and GSH are thiol compounds and can reduce disulfide bonds. In our study, DTT restored the growth of MS110 and MS111 more efficiently than GSH. DTT is known to be a strong reducing agent and can chemically reduce the other oxidized compounds containing disulfide bonds. On the other hand, the reducing power of GSH is somewhat weaker and this may involve other factors such

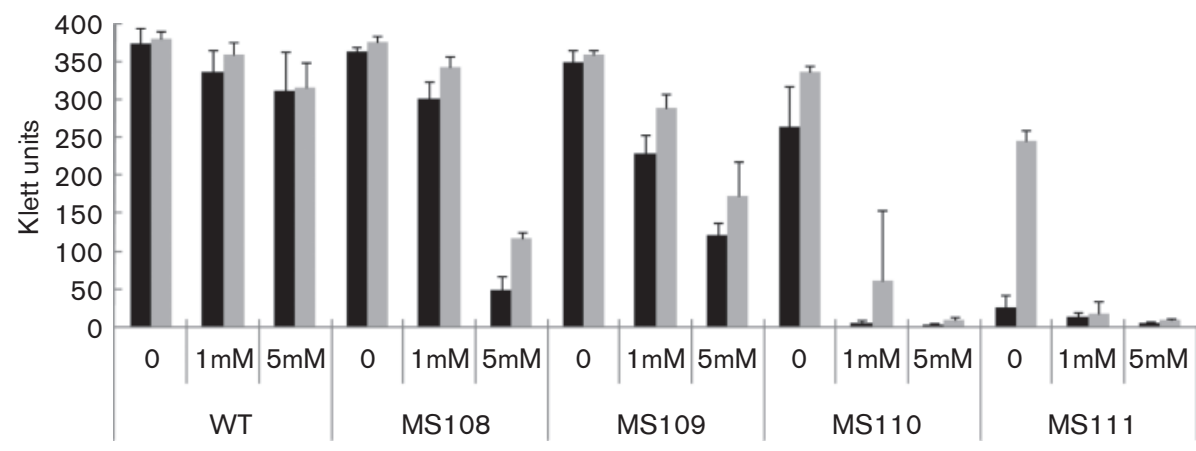

Fig. 5. Effect of adding diamide on the growth of $L$. casei strain Shirota and gene disruption mutants. Strains were grown in MRS under static aerobic condition (black bars) and under anaerobic condition (grey bars). Klett units were measured after $24 \mathrm{~h}$ incubation. The data are means \pm SD of at least three independent experiments. Strains: WT (wild-type), MS108 (trxA1 mutant), MS109 (trxA2 mutant), MS110 (trxA1 trxA2 double mutant) and MS111 (trxB mutant). 


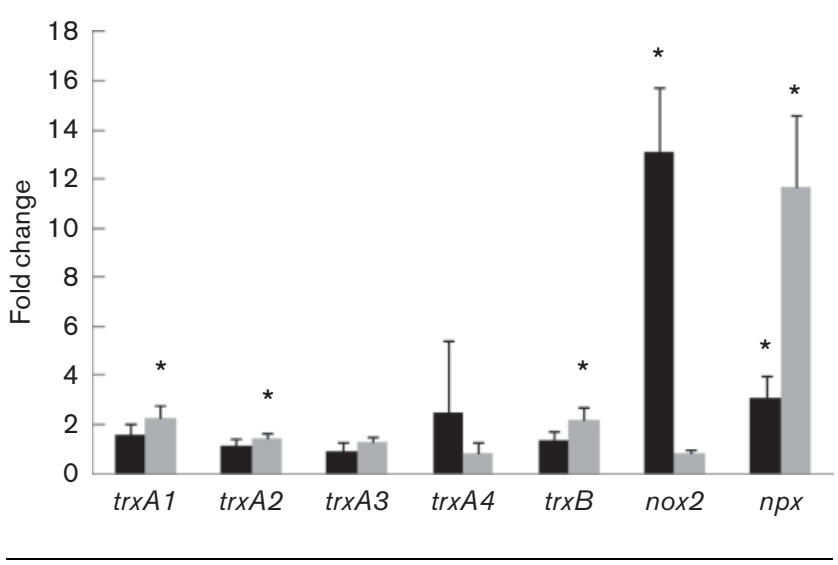

Fig. 6. Transcriptional analysis of thioredoxin and thioredoxin reductase genes. Bars represent the relative expression following exposure to oxygen compared with cells under anaerobic conditions (black bars) and the relative expression following exposure to hydrogen peroxide compared with cells under static aerobic conditions (grey bars). L. casei strain Shirota grown for $7 \mathrm{~h}$ under anaerobic condition was exposed for $30 \mathrm{~min}$ to oxygen provided by vigorous shaking at 160 r.p.m. L. casei strain Shirota grown for $7 \mathrm{~h}$ under static aerobic conditions was exposed for $30 \mathrm{~min}$ to $0.5 \mathrm{mM}$ hydrogen peroxide. RNA was isolated from three independent experiments. Quantitative PCR was performed in duplicate for each of three independent samples. The gene expression values were normalized using $16 \mathrm{~S}$ rRNA as internal standard. The results are shown as fold change compared with each control condition and are the means \pm SD of three independent experiments. Significant differences compared with unstressed control are indicated by an asterisk $(P<0.05)$.

as glutathione reductase and glutaredoxins, orthologous genes of which we have found in the genome of $L$. casei strains. However, we do not know yet how GSH can act on the recovery of the thioredoxin-deficient mutants.

GSH is not produced in many Gram-positive bacteria, including L. casei (Fahey et al., 1978). Although we have found a homologue of the GSH synthesis fusion protein (GshF) gene consisting of a $\gamma$-glutamylcysteine ligase (GshA) domain and an ATP-grasp domain as in Listeria monocytogenes and Streptococcus agalactiae (Gopal et al., 2005; Janowiak \& Griffith, 2005), it is still an open question whether or not L. casei strain Shirota can synthesize GSH. However, the fact that the growth defect of the $\operatorname{tr} x B$ mutant was restored by adding GSH under static aerobic conditions (Fig. 4) indicates that $L$. casei strain Shirota may not synthesize sufficient GSH and that a glutathione-glutaredoxin system does not function without adding GSH. In addition, we demonstrated that the $\operatorname{tr} x B$ mutant MS111 was sensitive to the thiol-oxidizing agent diamide even under anaerobic conditions (Fig. 5). As the thioredoxin reductase is essential to regenerate reduced thioredoxins, none of thioredoxins can function in a thioredoxin reductase-deficient mutant. Taken together, these results indicate that the thioredoxin-thioredoxin reductase system plays an essential role in maintaining the thiol/disulfide balance in $L$. casei.
Many organisms have been reported to have multiple thioredoxin genes (Akif et al., 2008; Comtois et al., 2003; Reott et al., 2009; Serrano et al., 2007). L. casei strain Shirota and all other sequenced $L$. casei strains except $L$. casei Zhang have four thioredoxin genes. The trxA1 mutant MS108 and the $\operatorname{trx} A 2$ mutant MS109 were slightly sensitive to oxidative stress, although the degree of sensitivity differed. The trxA1 $\operatorname{trx} A 2$ double mutant MS110 was more sensitive to oxidative stress than MS108 or MS109. MS111 was more sensitive to oxidative stress than MS110. From these results, we suggest that the effects of inactivation of $\operatorname{trx} A 1$ and $\operatorname{trx} A 2$ were additive, and the $\operatorname{tr} x A 3$ and/or trxA4 genes probably contribute in part to balance intracellular thiol/disulfide levels. In plant cells, it has been reported that they have different types of thioredoxins (Hisabori et al., 2007) and that thioredoxins have different substrate specificities in vitro (Collin et al., 2003). There is some possibility that each thioredoxin in L. casei strain Shirota has a different role the in cellular process, since the deduced amino acid sequences of the four thioredoxins have low amino acid identities with each other (Fig. 1), and the behaviour of MS108 and MS109 is different (Figs 3, 4 and 5). Further molecular and biochemical studies are needed to confirm this possibility in L. casei.

Unexpectedly, the growth of MS109, MS110 and MS111 was inhibited by adding $1 \mathrm{mM}$ cysteine (Fig. 4). This is not consistent with results reported for L. lactis, B. fragilis and $B$. subtilis (Möller \& Hederstedt, 2008; Rocha et al., 2007; Vido et al., 2005). Vido et al. (2005) reported that cystine did not affect the growth of $\operatorname{tr} x B$ mutant in L. lactis. When we added cystine to the cultures of MS110 and MS111 under anaerobic conditions, the growth of the $\operatorname{tr} x A 1 \operatorname{trx} A 2$ double mutant and the $\operatorname{tr} x B$ mutant was inhibited (data not shown). Thus, both cysteine and cystine have toxic effects on the growth of mutants defective in the thioredoxin-thioredoxin reductase system in $L$. casei. To date, we do not know the reasons for this. In order to elucidate the cysteine toxicity in L. casei strain Shirota, we need to carry out further studies.

In this study, we observed that the $\operatorname{tr} x A 1, \operatorname{tr} x A 2$ and $\operatorname{tr} x B$ genes were only weakly induced by hydrogen peroxide stress in $L$. casei, and all thioredoxin and thioredoxin reductase genes were not affected by oxygen stress (Fig. 6). However, thioredoxin and thioredoxin reductase genes were reported to be induced by oxidative stress in many bacteria. $B$. fragilis thioredoxin genes, $\operatorname{tr} x C, \operatorname{trx} E, \operatorname{tr} x F$ and $\operatorname{tr} x G$, were induced under aerobic conditions and thioredoxin reductase genes were induced by hydrogen peroxide or oxygen (Reott et al., 2009; Rocha et al., 2007). In order to protect against acute oxidative stress, $L$. casei has a response system that eliminates oxygen and hydrogen peroxide by immediately inducing NADH oxidase and NADH peroxidase. This may show that the facultative anaerobe $L$. casei could require enzymes such as NADH oxidase and NADH peroxidase under strong oxidative stress conditions. On the other hand, thioredoxins are always needed to maintain a certain level of reducing conditions among intracellular proteins involved in oxido-reduction reactions, irrespective of aerobic or anaerobic conditions. Taken together, the thioredoxin-thioredoxin reductase system in $L$. case $i$ has a pivotal 
role in sustaining microbial life by maintaining certain levels of the intracellular thiol/disulfide balance under both strong and weak oxidative stress conditions.

In conclusion, our study indicates that the thioredoxinthioredoxin reductase system is essential for aerobic growth of $L$. casei strain Shirota and is the major system for maintaining the intracellular thiol/disulfide balance.

\section{ACKNOWLEDGEMENTS}

We thank Mayumi Kiwaki of Yakult Central Institute for helpful discussions and suggestions.

\section{REFERENCES}

Ai, L., Chen, C., Zhou, F., Wang, L., Zhang, H., Chen, W. \& Guo, B. (2011). Complete genome sequence of the probiotic strain Lactobacillus casei BD-II. J Bacteriol 193, 3160-3161.

Akif, M., Khare, G., Tyagi, A. K., Mande, S. C. \& Sardesai, A. A. (2008). Functional studies of multiple thioredoxins from Mycobacterium tuberculosis. J Bacteriol 190, 7087-7095.

Altermann, E., Russell, W. M., Azcarate-Peril, M. A., Barrangou, R., Buck, B. L., McAuliffe, O., Souther, N., Dobson, A., Duong, T. \& other authors (2005). Complete genome sequence of the probiotic lactic acid bacterium Lactobacillus acidophilus NCFM. Proc Natl Acad Sci U S A 102, 3906-3912.

Arnér, E. S. \& Holmgren, A. (2000). Physiological functions of thioredoxin and thioredoxin reductase. Eur J Biochem 267, 6102-6109.

Asahara, T., Nomoto, K., Watanuki, M. \& Yokokura, T. (2001). Antimicrobial activity of intraurethrally administered probiotic Lactobacillus casei in a murine model of Escherichia coli urinary tract infection. Antimicrob Agents Chemother 45, 1751-1760.

Cai, H., Thompson, R., Budinich, M. F., Broadbent, J. R. \& Steele, J. L. (2009). Genome sequence and comparative genome analysis of Lactobacillus casei: insights into their niche-associated evolution. Genome Biol Evol 1, 239-257.

Carmel-Harel, O. \& Storz, G. (2000). Roles of the glutathione- and thioredoxin-dependent reduction systems in the Escherichia coli and Saccharomyces cerevisiae responses to oxidative stress. Annu Rev Microbiol 54, 439-461.

Chaillou, S., Champomier-Vergès, M. C., Cornet, M., Crutz-Le Coq, A. M., Dudez, A. M., Martin, V., Beaufils, S., Darbon-Rongère, E., Bossy, R. \& other authors (2005). The complete genome sequence of the meat-borne lactic acid bacterium Lactobacillus sakei $23 \mathrm{~K}$. Nat Biotechnol 23, 1527-1533.

Chang, S. K. \& Hassan, H. M. (1997). Characterization of superoxide dismutase in Streptococcus thermophilus. Appl Environ Microbiol 63, 3732-3735.

Chen, C., Ai, L., Zhou, F., Wang, L., Zhang, H., Chen, W. \& Guo, B. (2011). Complete genome sequence of the probiotic bacterium Lactobacillus casei LC2W. J Bacteriol 193, 3419-3420.

Collin, V., Issakidis-Bourguet, E., Marchand, C., Hirasawa, M., Lancelin, J. M., Knaff, D. B. \& Miginiac-Maslow, M. (2003). The Arabidopsis plastidial thioredoxins: new functions and new insights into specificity. J Biol Chem 278, 23747-23752.

Comtois, S. L., Gidley, M. D. \& Kelly, D. J. (2003). Role of the thioredoxin system and the thiol-peroxidases Tpx and Bcp in mediating resistance to oxidative and nitrosative stress in Helicobacter pylori. Microbiology 149, 121-129.
Fahey, R. C., Brown, W. C., Adams, W. B. \& Worsham, M. B. (1978). Occurrence of glutathione in bacteria. J Bacteriol 133, 1126-1129.

Goffin, P., Lorquet, F., Kleerebezem, M. \& Hols, P. (2004). Major role of NAD-dependent lactate dehydrogenases in aerobic lactate utilization in Lactobacillus plantarum during early stationary phase. J Bacteriol 186, 6661-6666.

Gopal, S., Borovok, I., Ofer, A., Yanku, M., Cohen, G., Goebel, W., Kreft, J. \& Aharonowitz, Y. (2005). A multidomain fusion protein in Listeria monocytogenes catalyzes the two primary activities for glutathione biosynthesis. J Bacteriol 187, 3839-3847.

Higuchi, M., Shimada, M., Yamamoto, Y., Hayashi, T., Koga, T. \& Kamio, Y. (1993). Identification of two distinct NADH oxidases corresponding to $\mathrm{H}_{2} \mathrm{O}_{2}$-forming oxidase and $\mathrm{H}_{2} \mathrm{O}$-forming oxidase induced in Streptococcus mutans. J Gen Microbiol 139, 2343-2351.

Higuchi, M., Yamamoto, Y., Poole, L. B., Shimada, M., Sato, Y., Takahashi, N. \& Kamio, Y. (1999). Functions of two types of NADH oxidases in energy metabolism and oxidative stress of Streptococcus mutans. J Bacteriol 181, 5940-5947.

Hisabori, T., Motohashi, K., Hosoya-Matsuda, N., Ueoka-Nakanishi, H. \& Romano, P. G. (2007). Towards a functional dissection of thioredoxin networks in plant cells. Photochem Photobiol 83, 145-151.

Holmgren, A. (1985). Thioredoxin. Annu Rev Biochem 54, 237-271.

Janowiak, B. E. \& Griffith, O. W. (2005). Glutathione synthesis in Streptococcus agalactiae. One protein accounts for gamma-glutamylcysteine synthetase and glutathione synthetase activities. J Biol Chem 280, 11829-11839.

Kiwaki, M. \& Shimizu-Kadota, M. (2002). Development of genetic manipulation systems and application to genetic research in Lactobacillus casei strain Shirota. Biosci Microflora 20, 121-129.

Kleerebezem, M., Boekhorst, J., van Kranenburg, R., Molenaar, D., Kuipers, O. P., Leer, R., Tarchini, R., Peters, S. A., Sandbrink, H. M. \& other authors (2003). Complete genome sequence of Lactobacillus plantarum WCFS1. Proc Natl Acad Sci U S A 100, 1990-1995.

Kono, Y. \& Fridovich, I. (1983). Isolation and characterization of the pseudocatalase of Lactobacillus plantarum. J Biol Chem 258, 6015-6019.

Kosower, N. S. \& Kosower, E. M. (1995). Diamide: an oxidant probe for thiols. Methods Enzymol 251, 123-133.

Laurent, T. C., Moore, E. C. \& Reichard, P. (1964). Enzymatic synthesis of deoxyribonucleotides. IV. Isolation and characterization of thioredoxin, the hydrogen donor from Escherichia coli B. J Biol Chem 239, 3436-3444.

Makarova, K., Slesarev, A., Wolf, Y., Sorokin, A., Mirkin, B., Koonin, E., Pavlov, A., Pavlova, N., Karamychev, V. \& other authors (2006). Comparative genomics of the lactic acid bacteria. Proc Natl Acad Sci U S A 103, 15611-15616.

Matsumoto, S., Hara, T., Hori, T., Mitsuyama, K., Nagaoka, M., Tomiyasu, N., Suzuki, A. \& Sata, M. (2005). Probiotic Lactobacillusinduced improvement in murine chronic inflammatory bowel disease is associated with the down-regulation of pro-inflammatory cytokines in lamina propria mononuclear cells. Clin Exp Immunol 140, 417-426.

Matsuzaki, T., Takagi, A., Ikemura, H., Matsuguchi, T. \& Yokokura, T. (2004). Antitumor activity and action mechanisms of Lactobacillus casei through the regulation of immune responses. Biofactors 22, 63-66.

Mazé, A., Boël, G., Zúñiga, M., Bourand, A., Loux, V., Yebra, M. J., Monedero, V., Correia, K., Jacques, N. \& other authors (2010). Complete genome sequence of the probiotic Lactobacillus casei strain BL23. J Bacteriol 192, 2647-2648.

Miyoshi, A., Rochat, T., Gratadoux, J. J., Le Loir, Y., Oliveira, S. C., Langella, P. \& Azevedo, V. (2003). Oxidative stress in Lactococcus lactis. Genet Mol Res 2, 348-359. 
Möller, M. C. \& Hederstedt, L. (2008). Extracytoplasmic processes impaired by inactivation of $\operatorname{tr} x A$ (thioredoxin gene) in Bacillus subtilis. J Bacteriol 190, 4660-4665.

Reott, M. A., Parker, A. C., Rocha, E. R. \& Smith, C. J. (2009). Thioredoxins in redox maintenance and survival during oxidative stress of Bacteroides fragilis. J Bacteriol 191, 3384-3391.

Rocha, E. R., Tzianabos, A. O. \& Smith, C. J. (2007). Thioredoxin reductase is essential for thiol/disulfide redox control and oxidative stress survival of the anaerobe Bacteroides fragilis. J Bacteriol 189, 8015-8023.

Sambrook, J. W. \& Russel, D. W. (2001). Molecular Cloning: a Laboratory Manual, 3rd edn. Cold Spring Harbor, NY: Cold Spring Harbor Laboratory Press.

Sanders, J. W., Leenhouts, K. J., Haandrikman, A. J., Venema, G. \& Kok, J. (1995). Stress response in Lactococcus lactis: cloning, expression analysis, and mutation of the lactococcal superoxide dismutase gene. J Bacteriol 177, 5254-5260.

Scharf, C., Riethdorf, S., Ernst, H., Engelmann, S., Völker, U. \& Hecker, M. (1998). Thioredoxin is an essential protein induced by multiple stresses in Bacillus subtilis. J Bacteriol 180, 1869-1877.

Sedewitz, B., Schleifer, K. H. \& Götz, F. (1984). Physiological role of pyruvate oxidase in the aerobic metabolism of Lactobacillus plantarum. J Bacteriol 160, 462-465.

Seki, M., lida, K., Saito, M., Nakayama, H. \& Yoshida, S. (2004). Hydrogen peroxide production in Streptococcus pyogenes: involvement of lactate oxidase and coupling with aerobic utilization of lactate. J Bacteriol 186, 2046-2051.

Seo, D., Kamino, K., Inoue, K. \& Sakurai, H. (2004). Purification and characterization of ferredoxin-NADP ${ }^{+}$reductase encoded by Bacillus subtilis yumC. Arch Microbiol 182, 80-89.
Serrano, L. M., Molenaar, D., Wels, M., Teusink, B., Bron, P. A., de Vos, W. M. \& Smid, E. J. (2007). Thioredoxin reductase is a key factor in the oxidative stress response of Lactobacillus plantarum WCFS1. Microb Cell Fact 6, 29.

Shida, K., Kiyoshima-Shibata, J., Nagaoka, M., Watanabe, K. \& Nanno, M. (2006). Induction of interleukin-12 by Lactobacillus strains having a rigid cell wall resistant to intracellular digestion. J Dairy Sci 89, 3306-3317.

Uziel, O., Borovok, I., Schreiber, R., Cohen, G. \& Aharonowitz, Y. (2004). Transcriptional regulation of the Staphylococcus aureus thioredoxin and thioredoxin reductase genes in response to oxygen and disulfide stress. J Bacteriol 186, 326-334.

van de Guchte, M., Penaud, S., Grimaldi, C., Barbe, V., Bryson, K., Nicolas, P., Robert, C., Oztas, S., Mangenot, S. \& other authors (2006). The complete genome sequence of Lactobacillus bulgaricus reveals extensive and ongoing reductive evolution. Proc Natl Acad Sci U S A 103, 9274-9279.

Vido, K., Diemer, H., Van Dorsselaer, A., Leize, E., Juillard, V., Gruss, A. \& Gaudu, P. (2005). Roles of thioredoxin reductase during the aerobic life of Lactococcus lactis. J Bacteriol 187, 601-610.

Yasuda, E., Serata, M. \& Sako, T. (2008). Suppressive effect on activation of macrophages by Lactobacillus casei strain Shirota genes determining the synthesis of cell wall-associated polysaccharides. Appl Environ Microbiol 74, 4746-4755.

Zhang, W., Yu, D., Sun, Z., Wu, R., Chen, X., Chen, W., Meng, H., Hu, S. \& Zhang, H. (2010). Complete genome sequence of Lactobacillus casei Zhang, a new probiotic strain isolated from traditional homemade koumiss in Inner Mongolia, China. J Bacteriol 192, 5268-5269.

Edited by: P. W. O'Toole 